\title{
ADVANCED QUALIFICATION TRAINING: A STUDY OF IMPLEMENTATION OF CRM INTO AIRLINE TRAINING
}

\author{
Roger C. Matteson \\ Central Washington University \\ Introduction
}

\begin{abstract}
The emphasis in training pilots on today's aircraft is placed on preparing the crew to interact with each other and to recognize any problem that may occur long before such a problem becomes a flight hazard. The training that is necessary to do this is called Crew Resource Management (CRM). Although CRM has been used by the airlines for about the past ten years, no integrated training among the airlines has been formulated until recently. Recent pressure from outside sources has prompted the FAA to initiate action to formalize CRM training in the airlines. The Federal Aviation Administration (FAA) established Special Federal Aviation Regulation (SFAR) 58, which created the Advanced Qualification Program (AQP) (Federal Aviation Administration, 1990). This allowed the airlines to develop their own training program which incorporates CRM and Line Operational Simulations (LOS). LOS utilizes simulator training using a typical operational passenger flight scenario, in a controlled training environment. It is designed to improve cockpit/cabin communication and coordination skills, and pilot decisionmaking skills (Federal Aviation Administration, 1995).
\end{abstract}

\section{Background of CRM}

In the early 1980s, Clay Foushee a NASA researcher, showed that communication between pilots in an automated aircraft was of great importance because of the systems complexity (Hughes, 1995). This was the beginning of implementing CRM into the training program of aircrew. Foushee's study goes on to suggest that information sharing among aircrew members is a key ingredient of CRM.

In another study covering the period from 1978 to 1990 , the National Transportation Safety Board (NTSB) investigators compared thirty-seven airline accidents and determined that in eight, flight crews were causal factors (Phillips, 1994). Communication breakdown between the aircrew was the main factor cited in all eight accidents. Recommendation from the study by NASA has resulted in increased emphasis on training the aircrew in CRM (Phillips, 1994).

From the period 1987 and 1992, large carrier accident rates have steadily declined by an average of greater than 0.1 accident per 100,000 hours of major airlines flying time (Federal Aviation Administration, 1996). This coincides with the start of CRM training in the airlines. Figure 1 illustrates the decrease of the accident rate in those years.

From the same period 1987 and 1992, commuter carrier accident rates have not shown any consistent pattern in decline or rise. CRM had not been used to any great extent during those years on commuter airlines. Figure 2 illustrates the accident rate in those years. 


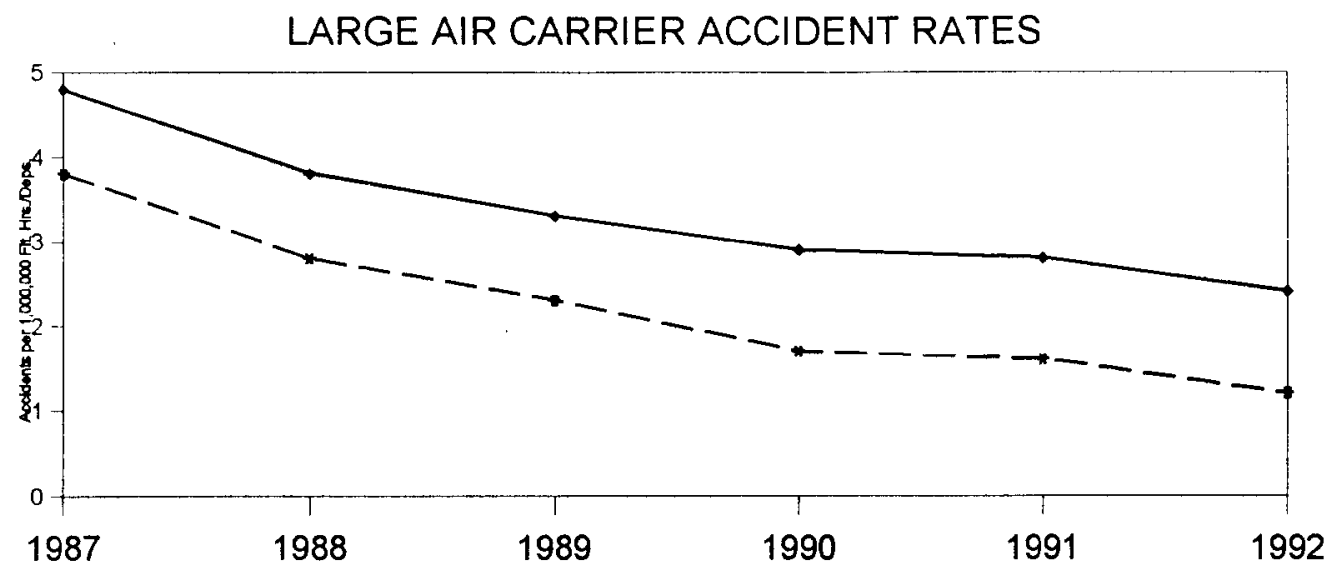

Source: National Transportation Safety Board

$\longrightarrow$ By flight hours $\rightarrow-$ By departures $-\cdot-$

Figure 1 (FAA, 1996) Large Carrier accident rates between 1987 and 1992.

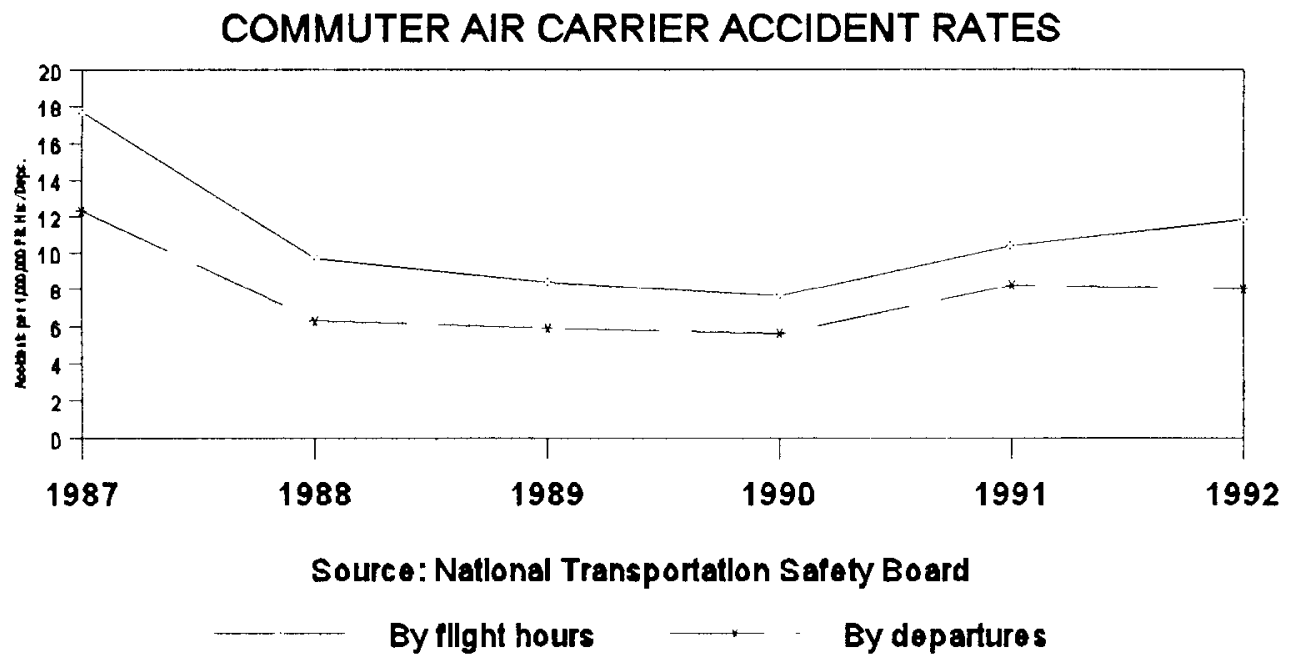

Figure 2 (FAA, 1996) Commuter Carrier accident rates between 1987 and 1992

\section{CRM Training and Implementation}

To begin to train aircrew in CRM, the screening process must take place from the initial interview of the applicant. After the screening, CRM is placed into two parts. The first part 
focuses on the individual and the second part as a member of the team. Training must be structured to address both individual and team level processes and behavior (Endsley, 1995). The individual phase concentrates on critical information seeking and information processing behaviors needed for individual situation assessment and awareness. For the team phase, training focuses on complex communication behaviors and team planning (Salas, Prince, Baker, \& Shrestha, 1995).

Many airlines have already placed a high emphasis on CRM. United Airlines has revised its policy on training aircrew. No longer does it focus on how the airplane works but more on how the aircraft team works. Aircraft have been getting more automated and the need for indepth knowledge of basic aircraft systems is de-emphasized (Scott, 1995).

\section{CRM as a Continuous Training Process}

CRM is an on-going process. The initial training of the crew is just the beginning. Different studies have suggested that on-going training or recurrency training be implemented. Suggestions from six months to one year have been stated. Studies have argued that performance during and shortly after training is less sensitive to personality effects than performance after long exposure to operational conditions (Helmreich, Sawin \& Carsrud, 1989). These same studies suggest that after initial training most people are motivated and want to do as good as job as possible. However, over time the job may become more routine. Initial motivation decline and personality characteristics, such as intrinsic achievement motives, may become more important predictors of performance (Helmreich, Chidester, Gregorich, \& Geis, 1991).

\section{Initiating Early Training of CRM}

Crew-oriented training is emerging as the preferred method to be followed from the time a student takes the first flying lesson until sitting in the cockpit of a large transport. The emphasis on human factors is driven by the fact that $65 \%$ of jet transport accidents are caused by human error (Hughes, 1989). Introducing CRM from the beginning of the process allows for the early introduction of human factor related training, which teaches pilots to communicate effectively and to work as a team.

The University of North Dakota, in conjunction with Northwest Airlines, developed a curriculum for students with no prior flying experience who are planning on becoming airline pilots. CRM plays a major role in the new curriculum, which consists of three separate courses (Hughes, 1989). The courses range from the students critiquing each other's performance to changing roles from captain to co-pilot. Simulators are mostly used for the role reversal with some time in actual aircraft. An evaluator or instructor sits in back to evaluate their overall performance.

\section{Incorporating AQP into Airline Training Programs}

The development of AQP started in the 1980s. Numerous accidents in the 1970s and 1980 s were attributed to communication and management problems of the flight crew. The 1980 s were a few of the worst years in terms of accidents for the airlines. This led the FAA administrator, T. Allan McArtor, in 1987 to request that aviation related special interest groups get together and find a solution to these accidents (Tenney, 1992). These groups determined that the training and the way in which training was conducted was a major factor that could be 
improved in order to increase the safety of the airlines. From this, SFAR 58 evolved and was signed into legislature by FAA administrator James B. Busey in 1989 (Tenney, 1992). SFAR 58 created $A Q P$, which institutes the ability for an airline to develop their own training program incorporating CRM and LOS.

An AQP is a program developed by an airline that is specific to that airline and aircraft type. The program focuses on certain items in the training that are neglected under current training standards in Part 121 and Part 135. Added emphasis is placed upon CRM, LOS, communication skills and advanced training equipment (Federal Aviation Administration, 1991). The training that is conducted under AQP focuses on training as a crew and develops coordination skills required of the crew.

\section{Simulator and Computer Use in AQP}

The use of Simulator-based training (SBT) and Computer-based training (CBT), are being implemented and heavily relied upon when training in AQP. The primary reason for using this ground based equipment is financial savings and time. CBTs are simulations that create real-world environments on desk-top computers or low cost trainers to teach skills such as mastery of complex flight management systems (Henderson, 1996). SBT integrates courseware associated with traditional CBT and the fidelity of full flight simulator software. The SBT also can feature graphic display workstations, large projection screens and instructor stations to the host simulator's real-time simulation models (Orlady, 1994).

There have been substantial advances in virtually all CBT areas, and there continues to be further technological increases in the field. According to Orlady, among the advantages attributed to such training are the following:

1. It is more economical than lecture-type instruction.

2. It ensures that all trainees receive the same and correct information.

3. It does not require large numbers of expert instructors.

4. It reduces undesirable pressure on trainees by permitting them to proceed at their own pace (1994).

Due to the introduction of the CD-ROM, CBT has expanded itself to interactive multimedia. According to Bill Thomas, director of operations at the Air Transport Association, CBT will become even more widespread as airlines move into proficiency-based training under AQP (Henderson, 1996). One of the main interests in CBT is the reduction of time spent in training and the initial increase in proficiency from the pilots. R. Blayloch, director of learning technologies research for American Airlines, states that a two week training course can be cut in half by changing from lecture to interactive multimedia. Blayloch states that this would have a possible learning improvement of about 30\% (Henderson, 1996).

\section{Current Issues of AQP}

Airline training costs are a large portion of the expenses that an airline incurs in its operation. Many airlines would be genuinely interested in a method of reducing these costs, but they appear to be ever-growing with increased regulations. Recent proposed rule makings by the FAA will make training costs skyrocket, leaving many smaller airlines operating small and diverse fleets on the verge of financial bankruptcy. In order to trim costs on training, many airlines have utilized outside assistance from training centers such as Flight Safety International, Simuflight and Avtar. These centers may have a more definitive future in the training of airline pilots since the FAA made AQP mandatory in the airline's training. 
Due to the lack of any standardized training among the airlines, Rep. James L. Oberstar (D. MN), chairman of the House aviation subcommittee, at a safety conference in Washington, D. C. suggested that AQP be mandatory (Hughes, 1995). This prompted the FAA to submit a Notice of Proposed Rule Making (NPRM). NPRM : Air carrier and commercial operator program (AC 120-54; AFS-210) became effective March 19, 1996 (Federal Aviation Administration, 1995). The NPRM makes the use of CRM and LOS mandatory for Part 121 Certified Carriers, and Part 135 Commuter Air Carriers who operate aircraft requiring two or more flight crew members and/or operate aircraft of 10 or more seats (Hughes, 1995). This is the first time the FAA has proposed any regulation towards making CRM or LOS training mandatory for the airlines. In the past, the FAA has only suggested that the airlines follow guidelines set up by them.

In the NPRM, the FAA has researched the potential savings that the Part 121 and Part 135 operators would save by the decrease in the accident rate over a period of ten years by implementing AQP. The initial training costs for some Part 135 operators would be high due to implementation of the training program, but the long term savings would eventually offset any up-front cost. The question would be if the operators could survive long enough to see the long term savings.

Over the next ten years, the FAA projects the total discounted value of benefits from implementing AQP to be $\$ 305$ million for both Part 121 and 135 operators (Federal Aviation Administration, 1995). The FAA estimates the benefits from requiring AQP training for Part 135 pilots to be $\$ 98$ million from 1995 to 2004 . The cost of implementing the training would range from an $\$ 9$ to $\$ 12$ million. This would make the long term benefits to be substantial (Federal Aviation Administration, 1995).

\section{Possible Problem with AQP}

As suggested earlier in the research, a major obstacle is the initial cost of setting up AQP training centers. The major airlines have the resources available to set up these programs and initiate training without too much of a financial burden. Some commuter airlines do not have the luxury of having large resources to fund such training programs. One of the initial concerns when the FAA established procedures for establishing AQP was the possible financial burden to the smaller commuter airlines.

\section{Conclusion}

It is evident that the pilot of today does need a multifaceted training program to operate today's complex aircraft. They need the technical skills that have always been needed to fly the aircraft, judge weather conditions, apply aerodynamics, handle emergencies, and navigation skills. The pilot also needs the interaction skills that were discussed in this paper that they would receive from $C R M$ training. Putting the two training formats together and measuring those skills is what AQP is all about. Not until the last three years have the airlines been able to develop such programs for more effective and comprehensive training of their pilots. 


\section{References}

Endsley, M. R. (1995). A survey of situation awareness requirements in air to air combat fighters. International Journal of Aviation Psychology, 3, 157-168.

Federal Aviation Administration. (1990, October 2). SFAR 58: Advanced

qualification program (Part 121; SFAR 58). Washington, DC: Author.

Federal Aviation Administration. (1991, August 9). AC120-54: Advanced

qualification program (AC120-54; AFS-210). Washington DC: Author.

Federal Aviation Administration. (1995, December 8). NPRM: Air carrier and

commercial operator programs (Docket No. 27993; Notice No. 94-35). Washington DC: Author.

Federal Aviation Administration. (1996, February 14). Federal Aviation Administration

Statistical Handbook of Aviation. Washington DC: Author.

Helmreich, R. L., Chidester, T. R., Gregorich, S. E., \& Geis, C. E. (1991). Pilot

personality and crew coordination: Implications for training and selection. The International Journal of Aviation Psychology, $1,25-44$.

Helmreich, R. L., Sawin, P. L., \& Carsrud, T. C. (1989). How effective is cockpit

resource management training? NASA/University of Texas Tech. Rep., $2,10-22$.

Henderson, D. K. (1996, April). 'Virtual' work. Air Transport World, 33, 69-71.

Hughes, D., (1989, October 16). New approaches to pilot training stress human factors,

coordination. Aviation Week and Space Technology, 131, 86-87.

Hughes, D. (1995, January 16). FAA may make AQP mandatory. Aviation Week and

Space Technology, 142, 27.

Orlady, H. W. (1994, April). Airline pilot training programs have undergone important and necessary changes in the past decade. ICAO Journal, 5-10.

Phillips, E. H., (1994, February 14). NTSB urges more flight crew training. Aviation Week and Space Technology, 141, 40.

Salas, E., Prince, C., Baker, D. P., \& Shrestha, L. (1995). Situation awareness in team

performance: Implications for measurement and training. Human Factors, 37, 123-136.

Scott, W. B., (1995, February 6). United training stresses cockpit discipline. Aviation Week and Space Technology, 142, 50-51.

Tenney, D. P. (1992, April). Advanced qualification program customizes cockpit management. Professional Pilot, 70-73. 